\title{
VALORES ENERGÉTICOS DO FARELO DE SOJA PARA GALINHAS POEDEIRAS EM FUNÇÃO DOS NÍVEIS DE INCLUSÃO E DE PROTEÍNA BRUTA NA RAÇÃO REFERÊNCIA
}

\author{
(Energy values of the soybean meal for laying hens in function of the levels \\ of inclusion and of crude protein in the reference diet)
}

\author{
DEBASTIANI, M.'; NUNES, R.V.2; POZZA, P.C.2; POZZA, M.S.S; SILVA, J.D.'; NUNES, \\ C.G.V.; OELKE, C.A. ${ }^{4}$; VENTURI, I. ${ }^{1}$
}

${ }^{1}$ Acadêmicos do Curso de Zootecnia - UNIOESTE

2 CCA da UNIOESTE

3 Médica Veterinária da COPAGRIL

${ }^{4}$ Aluna de Pós Graduação em Ciências Veterinárias - UFPR

\begin{abstract}
RESUMO - O presente trabalho objetivou avaliar os valores de energia metabolizável aparente (EMA), energia metabolizável aparente corrigida pelo balanço de nitrogênio (EMA $\left.{ }_{n}\right)$, os coeficientes de metabolizabilidade da energia aparente (CMA) e aparente corrigida pelo balanço de nitrogênio $\left(\mathrm{CMA}_{n}\right)$ do farelo de soja, determinados com poedeiras. $O$ ensaio foi constituído de um alimento teste (farelo de soja) e duas rações referências. O farelo de soja substitui em 7,5 e 15,0\% duas rações referência contendo 14,0 e $19,0 \%$ de PB. Para determinação dos valores de EMA e EMAn foi utlizado o método de coleta total de excretas, onde 72 poedeiras Isabrown foram distribuídas em um delineamento experimental em blocos ao acaso num esquema fatorial $2 \times 2$ (nível de substituição do farelo de soja $x$ nível de PB da ração referência). Houve interação significativa $(P<0,05)$ entre os níveis de substituição do farelo de soja e os níveis de PB da ração referência. Através dos resultados obtidos nesse estudo, pode-se inferir que os valores para EMA, EMAn, CMA e CMAn são influenciados pelos níveis de proteína bruta da ração referência (14 e 19\%), e também pelo nível de substituição (7,5 e 15\%) do farelo de soja.
\end{abstract}

Palavras-Chaves: energia metabolizável; farelo de soja; inclusão; poedeiras.

ABSTRACT -This study had the objective to evaluate the values of apparent metabolizable energy (AME) and nitrogen corrected apparent metabolizable $\left(\mathrm{AME}_{\mathrm{n}}\right)$, apparent metabolizability coefficient (AMC) and nitrogen corrected apparent metabolizability coefficient $\left(\mathrm{AMC}_{n}\right)$ of soybean meal, determined with laying hens. The assay was constituted of a food test (soybean meal) and two reference diets. The soybean meal replaced a total of $14 \%$ and $19 \%$ of crude protein (CP) reference diet at the amount $7,5 \%$ of and $15 \%$. To determin the values of $A M E$ and $A M E_{n}$, has been used the total excreta colletion method, where 72 laying isabrown hens, were shared experimental random blocks design in a factorial outline 2x2 (substitution level of soybean meal X CP level of the reference diet). There was significant interaction $(P<0,05)$ between the substitution levels of soybean meal and the CP levels of the reference diet. Through the results gotten in this study, it can be inferred that the values for EMA, EMAn, CMA and CMAn are influenced by the crude protein levels in the ration reference $(14$ and $19 \%)$, and also for the level of substitution (7,5 and $15 \%$ ) of the soybeam meal in the ration.

Key-Words: metabolizable energy; soybeam meal; inclusion.

\section{INTRODUÇÃO}

Para STRINGHINI et al. (2005), a nutrição de poedeiras comerciais é uma importante ferramenta para a garantia dos níveis elevados de produção, atingidos pelas linhagens comerciais modernas. Sendo que a energia metabolizável dos alimentos é fator muito importante a ser considerado.

Para tanto, como conceitua-se energia metabolizável aparente (EMA) sendo a energia bruta do alimento menos a energia bruta das fezes, urina e dos produtos gasosos da digestão. Para as aves, a energia perdida na forma de gases é insignificante 
Valores Energéticos do Farelo de Soja para Galinhas

Poedeiras em Função dos Níveis de Inclusão e de Proteína Bruta na Ração Referência

sendo que a mesma pode ser ignorada.

E ainda, a energia metabolizável aparente corrigida pelo balanço de nitrogênio (EMAn) reduz a variação que pode ocorrer entre os valores de EMA do alimento, quando determinados com aves de diferentes espécies, linhagem e idades, pois, aves com diferentes graus de retenção de nitrogênio têm diferentes valores para energia excretada para um mesmo alimento (PENZ et al., 1999).

Este estudo foi realizado com o objetivo de avaliar os valores de energia metabolizável aparente (EMA), energia metabolizável aparente corrigida pelo balanço de nitrogênio $\left(E M A_{n}\right)$, e coeficientes de metabolizabilidade da energia aparente (CMA) e coeficientes de metabolizabilidade aparente corrigida $\left(\mathrm{CMA}_{n}\right)$ do farelo de soja, determinados com poedeiras, em dietas com diferentes níveis de proteína bruta e de substituição do alimento.

\section{MATERIAL E MÉTODOS}

O presente estudo foi realizado em uma granja comercial no município de Marechal Cândido Rondon - PR, entre maio e junho de 2004. Utilizou-se um alimento teste (farelo de soja) e duas rações referências, calculadas segundo as exigências descritas por ROSTAGNO et al. (2000). A composição centesimal das rações referências está descrita na Tabela 1.

As rações referências foram formuladas com níveis de 14,0 e $19,0 \%$ de PB e o farelo de soja substituiu em 7,5 e $15,0 \%$ as rações referências, totalizando assim, seis tratamentos, sendo quatro rações teste e duas rações referências.
Utilizaram-se 72 aves da linhagem Isabrown (poedeiras semipesadas) com 24 semanas de idade, distribuídas em um delineamento experimental em blocos ao acaso, em um esquema fatorial 2x2 (nível de $\mathrm{PB}$ da ração x nível de substituição do farelo de soja). Foram utilizados dois blocos ao acaso, distribuídos no tempo. Sendo realizada duas repetições por bloco e três aves por unidade experimental.

Alojaram-se as aves em gaiolas metálicas, distribuídas lateralmente em um galpão convencional para galinhas poedeiras. Foram utilizados bebedouro tipo calha de PVC, onde a água percorria toda a extensão frontal da gaiola, e comedouro tipo calha de madeira, disposto sob o bebedouro. As aves tiveram acesso a água e ração experimental á vontade.

O método utilizado para determinação dos valores de energia metabolizável aparente (EMA) e aparente corrigida $\left(E_{n} A_{n}\right)$ foi o de coleta total de excretas. As aves foram submetidas a um período de cinco dias de adaptação às rações e cinco dias de coleta total de excreta, sendo essa realizada as 8 e 17 horas. Para as coletas utilizaram-se bandejas metálicas cobertas com plástico, sob as gaiolas. Depois de coletadas, as excretas foram acondicionadas em sacos plásticos, e armazenadas em freezer $\mathrm{a}-5^{\circ} \mathrm{C}$.

Ao término da fase experimental, determinou-se o consumo de alimento. E as excretas foram descongeladas, pesadas, homogeneizadas e retiradas amostras para análises.

As análises químicas determinaram os valores de matéria seca, nitrogênio e de energia bruta do alimento, das rações referência e das excretas, segundo a metodologia descrita por SILVA e QUEIROZ (2002). 
Os valores de EMA e EMA foram calculados pelas equações propostas por MATTERSON et al. (1965). Os coeficientes de metabolizabilidade da energia bruta, em relação aos valores de EMA e EMA $A_{n}$, foram calculados segundo LEESON e SUMMERS (2001).

TABELA 1. COMPOSIÇÃO DAS RAÇÕES REFERÊNCIAS, EM PORCENTAGEM NA MATÉRIA NATURAL

\begin{tabular}{|c|c|c|}
\hline Ingredientes (\%) & $\begin{array}{c}\text { Ração } \\
\text { referência-1 }\end{array}$ & $\begin{array}{c}\text { Ração } \\
\text { referência-2 }\end{array}$ \\
\hline Milho & 52,87 & 69,23 \\
\hline Farelo de Soja & 32,50 & 17,77 \\
\hline Óleo Vegetal & 3,00 & 0,50 \\
\hline Fosfato Bicálcico & 2,14 & 2,11 \\
\hline Calcário & 8,46 & 8,59 \\
\hline DL-Metionina (99\%) & 0,28 & 0,21 \\
\hline L-Lisina HCL & - & 0,13 \\
\hline L-Triptofano & - & 0,02 \\
\hline Sal comum & 0,53 & 0,55 \\
\hline Cloreto de Colina $60 \%$ & 0,02 & 0,02 \\
\hline Suplemento Vitamínico ${ }^{1}$ & 0,12 & 0,12 \\
\hline Suplemento Mineral ${ }^{2}$ & 0,07 & 0,07 \\
\hline Antioxidante $^{3}$ & 0,01 & 0,01 \\
\hline Inerte ${ }^{4}$ & - & 0,67 \\
\hline TOTAL & 100,00 & 100,00 \\
\hline \multicolumn{3}{|c|}{ Composições calculadas } \\
\hline Energia Metabolizável $\left(\mathrm{kcal} \mathrm{kg}^{-1}\right)$ & 2.800 & 2.800 \\
\hline Proteína Bruta (\%) & 19,00 & 14,00 \\
\hline Lisina digestível (\%) & 0,93 & 0,72 \\
\hline Metionina digestível (\%) & 0,55 & 0,42 \\
\hline Metionina + Cistina digestível (\%) & 0,81 & 0,63 \\
\hline Treonina digestível (\%) & 0,66 & 0,47 \\
\hline Triptofano digestível (\%) & 0,22 & 0,16 \\
\hline Cálcio (\%) & 3,90 & 3,90 \\
\hline Fósforo disponível (\%) & 0,50 & 0,50 \\
\hline Sódio (\%) & 0,25 & 0,25 \\
\hline
\end{tabular}

1CONTEUDO KG-1: VIT. A 10.000.000 UI; VIT. D3 2.200.000 UI; VIT. E 6.000 UI; VIT. K 1,4 G; VIT. B1 1,4 G; VIT. B2 4,0 G; VIT. B6 1,8 G; VIT. B12 15.000 MCG; ÁCIDO NICOTÍNICO 25,0 G; ÁCIDO FÓLICO 0,4 G; ÁCIDO PANTOTÊNICO $8,5 \mathrm{G} ; \mathrm{SE} 0,3 \mathrm{G}$;

2 CONTEÚDO KG-1: MN 150 G; ZN 100 G; FE 100 G; CU 16 G; I 1,5 G;

3 BHT (HIDROXI BUTIL TOLUENO);

4AREIA LAVADA.

Como procedimento estatístico, utilizou-se o teste de comparação de médias de Student Newman-Keuls, a $5 \%$ de probabilidade, entre os valores médios de $E M A, E M A_{n}, C M A$ e $C M A_{n}$ para os diferentes níveis de $P B$ da ração e de substituição do farelo de soja, por intermédio do Sistema de Análises Estatísticas e Genéticas - SAEG (Universidade Federal de Viçosa, 1999). 
Valores Energéticos do Farelo de Soja para Galinhas

Poedeiras em Função dos Níveis de Inclusão e de Proteína Bruta na Ração Referência

\section{RESULTADOS E DISCUSSÃO}

A analises estatísticas revelaram que não houve influencia $(P>0,05)$ do bloco nas variáveis estudadas.

\section{COMPOSIÇÃO QUÍMICA}

Os valores da composição química e energia bruta do farelo de soja utilizado nesse estudo estão apresentados na TABELA 2.

TABELA 2. COMPOSIÇÃO QUÍMICA E VALORES DE ENERGIA BRUTA DO FARELO DE SOJANA MATÉRIA NATURAL

\begin{tabular}{lcccccc}
\hline Alimento & MS (\%) & EB (kcal kg-1) & PB (\%) & EE (\%) & MM (\%) & FB (\%) \\
\hline Farelo de Soja & 93,97 & 4.024 & 47,08 & 2,52 & 6,18 & 3,68
\end{tabular}

MS = MATÉRIA SECA; EB = ENERGIA BRUTA; PB = PROTEÍNA BRUTA; EE = EXTRATO ETÉREO; MM= MATÉRIA MINERAL OU CINZA; FB = FIBRA BRUTA.

O teor PB do farelo de soja analisado no presente trabalho foi de $47,08 \%$, sendo o mesmo menor do que aqueles descritos pela EMBRAPA (1991) e ROSTAGNO et al. (2005) que são respectivamente 47,8 e $47,9 \%$. Segundo ALBINO e SILVA (1996) a composição química dos alimentos pode ser dependente de vários fatores, como solo, clima, condições de colheita, armazenagem e tipo de processamento.

O farelo de soja em estudo apresentou valores 6,5 e $7,5 \%$ superiores no teor de matéria seca, quando comparado com os valores descritos pela EMBRAPA (1991) e ROSTAGNO et al. (2005), respectivamente.
A fibra bruta (FB) apresentou valor inferior àqueles descritos por EMBRAPA (1991) e ROSTAGNO et al. (2005), que foram de 5,68 e 4,25\%, respectivamente. Esta redução no teor de FB pode ser explicada pela menor inclusão de cascas de soja durante o processamento.

1. Valores de energia metabolizável aparente e aparente corrigida pelo balanço de nitrogênio:

Os valores de energia metabolizável aparente (EMA) e aparente corrigida pelo balanço de nitrogênio $\left(E M A_{n}\right)$ estão apresentados na Tabela 3. TABELA 3. VALORES DE ENERGIA METABOLIZÁVEL APARENTE (EMA) E APARENTE CORRIGIDA $\left(\text { EMA }_{N}\right)^{1}$
DO FARELO DE SOJA ${ }^{2}$

\begin{tabular}{|c|c|c|}
\hline \multirow{3}{*}{ Ração referência } & \multicolumn{2}{|c|}{$\operatorname{EMA}(\mathrm{CV}=11,87)$} \\
\hline & \multicolumn{2}{|c|}{ Nível de substituição (\%) } \\
\hline & 7,5 & 15 \\
\hline $14 \%$ de $\mathrm{PB}$ & $1.845^{\mathrm{bB}}$ & $2.249 \mathrm{bB}$ \\
\hline \multirow[t]{2}{*}{$19 \%$ de PB } & 3.636 aA & $3.182 \mathrm{aA}$ \\
\hline & \multicolumn{2}{|c|}{$\mathrm{EMA}_{n}(\mathrm{CV}=10,49)$} \\
\hline \multirow[t]{2}{*}{ Ração referência } & \multicolumn{2}{|c|}{ Nível de substituição (\%) } \\
\hline & 7,5 & 15 \\
\hline $14 \%$ de $P B$ & $1.552 \mathrm{dD}$ & $1.963^{c C}$ \\
\hline $19 \%$ de $\mathrm{PB}$ & $3.202 \mathrm{aA}$ & $2.794 \mathrm{bB}$ \\
\hline
\end{tabular}

1valores expressos em kcal kg-1 de matéria natural.

2médias seguidas de letras distintas (maiúsculas na coluna e minúsculas nas linhas) diferem entre si pelo teste de snk, ao nível de $5 \%$ de probabilidade.

Houve diferença significativa $(P<0,05)$ entre os tratamentos utilizados. Os valores de EMA aumentaram quando o nível de $\mathrm{PB}$ da ração referência variou de 14 para $19 \%$, entretanto, não foram observadas diferenças entre os níveis de inclusão do farelo de soja para as rações de mesmo nível de PB.
Observa-se grande variação nos valores de EMA encontrados quando comparados com os valores da literatura nacional (EMBRAPA, 1991; ROSTAGNO et al., 2000) e estrangeira (JANSSEN, 1989; NRC, 1994). O valor de EMA que mais se aproximou daqueles citados nas literaturas acima foi o de $2.249 \mathrm{kcal} \mathrm{kg}^{-1}$ 
de $\mathrm{MN}$, encontrado quando o farelo de soja foi incluído em $15 \%$ na ração referência de $14 \%$ de PB.

Para a EMA $A_{n}$ a interação entre os níveis de PB da ração referência e os níveis de inclusão do farelo de soja foi significativa. Os valores foram diferentes estatisticamente $(P<0,05)$, demonstrando haver uma interação entre os níveis de $\mathrm{PB}$ da ração e os níveis de inclusão do farelo de soja sobre os valores de EMA ${ }_{n}$ encontrados.

$O$ valor de $\mathrm{EMA}_{n}$ que mais se aproximou da literatura consultada foi o de $2.794 \mathrm{kcal} / \mathrm{kg}$ de $\mathrm{MN}$, obtido com a ração de $19 \%$ de PB e $15 \%$ de inclusão. Este valor está próximo daquele descrito por PENZ et al. (1999), que foi de $2.678 \mathrm{kcal} \mathrm{kg}^{-1}$ de MN, determinado com galinhas poedeiras com 32 semanas de idade. Porém, ambos valores são maiores do que aquele descrito por ROSTAGNO (2005), que é de $2.302 \mathrm{kcal} \mathrm{kg}^{-1}$.

ROSTAGNO (1990), trabalhando com poedeiras, encontrou diferenças nos valores de EMA ${ }_{n}$ do farelo de soja, sendo estes maiores com 32 do que com 12 semanas de idade das aves.

Quando se utilizou o nível de $19 \%$ de PB na ração com substituição de $15 \%$ do farelo de soja, o valor de $E M A_{n}$ encontrado foi menor do que no nível de $7,5 \%$ de substituição. O nível de inclusão de $15 \%$ de farelo de soja elevou a PB da dieta teste para $23,21 \%$, enquanto que o nível de $7,5 \%$ elevou a PB para $21,11 \%$. O NRC (1994), preconiza que se a proteína está em excesso, a energia metabolizável decresce porque os aminoácidos que não são utilizados para a síntese protéica são catabolizados e utilizados como fonte de energia e o conteúdo de nitrogênio é excretado na forma de ácido úrico. As- sim sendo, ao passo que o conteúdo de nitrogênio das excretas aumenta, ocorre uma diminuição nos valores de EM do alimento.

No entanto, o oposto foi verificado para a ração de $14 \%$ de PB. Neste caso, quando o nível de inclusão foi maior (15\%), elevando a PB da dieta teste para $18,96 \%$, o valor observado para a EMA aumentou, comparado com o nível de inclusão de $7,5 \%$, o qual modificou a PB da dieta teste para $16,48 \%$.

Isto pode ser explicado, pois a exigência de proteína para poedeiras é sugerida apenas como um ponto de referência, entretanto, a dieta deve conter uma quantidade suficiente de aminoácidos essenciais para assegurar um satisfatório pool de nitrogênio para a síntese protéica (NRC, 1994). Portanto as modificações que ocorreram no teor de PB das rações referências, após a inclusão do farelo de soja, podem explicar apenas parcialmente a variação obtida para os valores de $E M A_{n}$, devendo-se observar o conteúdo de aminoácidos destas dietas.

2. Coeficientes de metabolizabilidade:

$\mathrm{Na}$ Tabela 4, estão apresentados os coeficientes de metabolizabilidade da energia aparente (CMA) e aparente corrigida $\left(\mathrm{CMA}_{n}\right)$ do farelo de soja.

Houve diferença significativa $(P<0,05)$ entre os CMA nos diferentes níveis de proteína da ração referência. Quando a ração continha um menor teor de proteína, a maior inclusão do alimento resultou em melhor aproveitamento da energia bruta. No entanto, quando o teor de PB da ração foi de 19\%, a inclusão de $15 \%$ do farelo de soja, demonstrou menor aproveitamento da energia bruta pois, o excesso protéico pode ser catabolizado como ácido úrico, diminuindo assim o valor de energia metabolizável da dieta.

TABELA 4. COEFICIENTES DE METABOLIZABILIDADE APARENTE (CMA) E APARENTE CORRIGIDA $\left(\mathrm{CMA}_{\mathrm{N}}\right)$ DO FARELO DE SOJA ${ }^{1,2}$

\begin{tabular}{|c|c|c|}
\hline \multirow[b]{2}{*}{ Ração referência } & \multicolumn{2}{|c|}{ CMA - substituição (\%) } \\
\hline & 7,5 & 15 \\
\hline $14 \%$ PB & $45,84^{\mathrm{bB}}$ & 55,89 bв \\
\hline \multirow[t]{2}{*}{$19 \%$ PB } & $90,37^{\mathrm{aA}}$ & $79,07^{\mathrm{aA}}$ \\
\hline & \multicolumn{2}{|c|}{$\mathrm{CMA}_{\mathrm{n}}$ - substituição (\%) } \\
\hline Ração referência & 7,5 & 15 \\
\hline $14 \%$ PB & $38,59 \mathrm{dD}$ & $48,79 \propto c$ \\
\hline $19 \%$ PB & 79,58 aA & 69,94 вв \\
\hline
\end{tabular}

'MÉDIAS SEGUIDAS DE LETRAS DISTINTAS (MAIÚSCULAS NA COLUNA E MINÚSCULAS NAS LINHAS) DIFEREM ENTRE SI PELO TESTE DE SNK, AO NÍVEL DE 5\% DE PROBABILIDADE.

${ }^{2}$ VALORES EXPRESSOS NA MATÉRIA NATURAL. 
Valores Energéticos do Farelo de Soja para Galinhas

Poedeiras em Função dos Níveis de Inclusão e de Proteína Bruta na Ração Referência

Para o $\mathrm{CMA}_{n}$ a interação entre o nível de inclusão do farelo de soja e o nível de PB da dieta foi significativa $(P<0,05)$. O melhor aproveitamento da energia bruta foi obtido com o nível de $19 \%$ de PB e $7,5 \%$ de substituição, revelando que, uma maior inclusão do farelo de soja pode ocasionar uma menor utilização da energia bruta.

O valor de $\mathrm{CMA}_{\mathrm{n}}$ encontrado por ROSTAGNO et al. (2000) para o farelo de soja foi de 60,68\% (não sei da onde sai esse valor), mais próximo do encontrado neste trabalho com o nível de $14 \%$ de PB e $15 \%$ de substituição. No entanto, ROCHA (2003) trabalhando com uma ração referência de $19 \%$ de PB e $15 \%$ de inclusão de diferentes amostras de farelo de soja, encontrou valores de $\mathrm{CMA}_{n}$ variando de 45,85 a $65,19 \%$.

A grande variação entre os valores dos CMA e $\mathrm{CMA}_{n}$ do farelo de soja demonstra que a utilização da energia pelas aves, foi dependente do nível de inclusão do alimento na dieta e do nível de PB.

\section{CONCLUSÕES}

Através dos resultados obtidos nesse estudo, pode-se inferir que os valores para energia metabolizável aparente (EMA), energia metabolizável aparente corrigido para o balanço de nitrogênio (EMAn), coeficiente de metabolizabilidade aparente (CMA) e o coeficiente de metabolizabilidade aparente corrigida para o balanço de nitrogênio (CMAn) são influenciados pelos níveis de proteína bruta na ração referência (14 e 19\%), e também pelo nível de substituição $(7,5$ e $15 \%)$ do farelo de soja na ração.

\section{REFERÊNCIAS}

ALBINO, L.F.T.; SILVA, M.A. Valores nutritivos de alimentos para aves e suínos determinados no Brasil. In: Simpósio internacional sobre exigências nutricionais de aves e suínos. Viçosa, 1996. Anais... Viçosa: Universidade Federal de Vicoça, 1996. p.303-318.

EMPRESABRASILEIRADE PESQUISAAGROPECUÁRIA - EMBRAPA - CNPSA. Tabela de composição química e valores energéticos de alimentos para suínos e aves. 3. ed. Concórdia: CNPSA, 1991. 97 p. (Documento, 19).

JANSSEN, W.M.A. European table of energy values for poultry feedstuffs. $3^{\text {rd }}$ edition, 84p. 1989.

LEESON, S.; SUMMERS, J.D. Scott's Nutrition of the Chicken. 4.ed., 2001, 591p.
MATTERSON, L.D., POTTER, L.M., STUTZ, M.W. et al. The metabolizable energy of feed ingredients for chickens. University of Connecticut Storrs. Agricultural Experiment Station Research Report, v.11, 11p, 1965.

NATIONAL RESEARCH COUNCIL - NRC. Committe on Animal Nutrition. Subcommitte on Poultry Nutrition. Washington, EUA. Nutrient Requirements of Poultry, 9.ed. Washington, National Academy os Sciences, 1994. 155p.

PENZ JR., A.M.; KESSLER, A.M.; BRUGALLI, I. Novos conceitos de energia para aves. In: SIMPÓSIO INTERNACIONAL SOBRE NUTRIÇÃO DE AVES, 1999, Campinas. Anais... Campinas, SP, p.1-24.

ROSTAGNO, H.S. Valores de composição de alimentos e exigências nutricionais utilizados na formulação de rações para aves. In: reunião anual da sociedade brasileira de zootecnia, 27, 1990, Piracicaba. Anais... Piracicaba: FEALQ, 1990, p. 11-30.

ROSTAGNO, H.S.; ALBINO, L.F.T.; DONZELE, J.L. Tabelas brasileiras para aves e suínos. Composição de alimentos e exigências nutricionais. Viçosa: UFV, 2000. 141p.

ROSTAGNO, H.S., ALBINO, L.F.T., DONZELE, J.L. Tabelas brasileiras para aves e suínos. Composição de alimentos e exigências nutricionais. 2.ed. Viçosa: UFV, 2005. 186p.

ROCHA, L.D. Valores energéticos do milho e do farelo de soja determinados com poedeiras na fase de produção. Marechal Cândido Rondon: Universidade Estadual do Oeste do Paraná, 2003. 22p. Monografia (Graduação em Zootecnia). Universidade Estadual do Oeste do Paraná, 2003.

STRINGHINI, J.H.; JARDIM FILHO, R.M.; PEDROSO, A.A. Nutrição no período de pré-postura, pico e pós-pico de poedeiras comerciais. COFERÊNCIA APINCO DE CIÊNCIA E TECNOLOGIA AVÍCOLA 2005. Santos. Anais... Santos - SP, FACTA, 2005, p. 171-189.

SILVA, D.J.; QUEIROS, A.C. Análises de alimentos: métodos químicos e biológicos. Viçosa: UFV, 2002. 235p.

UNIVERSIDADE FEDERAL DE VIÇOSA - UFV. CPD. SAEG - Sistema para análises estatísticas e genéticas. Viçosa: MG; 1999. 59p.

Recebido para publicação: $20 / 09 / 2006$ Aprovado: 